\title{
Comparative study of non reinforced staple line and reinforced staple line during laparoscopic sleeve gastrectomy
}

\author{
M.A.Shaban, H.R.Mosalam, M.M.Rezk and E.A.Abd El-Mabood \\ General Surgery, Dept., Faculty of Medicine, Benha Univ., Benha, Egypt \\ E-Mail: M.A.Shaban@yahoo.com
}

\begin{abstract}
Background: Staple line bleeding \& leak are the most annoying events of Laparoscopic Sleeve Gastrectomy. Staple line reinforcement (SLR) is considered a weapon to reduce the incidence of such dangerous events. Purpose: Rationale of this study is to compare between non reinforced and reinforced staple line with vicryl sutures during laparoscopic sleeve gastrectomy. Patients and methods: Patients were divided into two groups; group (A); 25 cases; underwent Laparoscopic Sleeve Gastrectomy (LSG) with strengthening of the stapler line by v-lock suture and group (B); 25 cases; underwent LSG without reinforcement of stapler line. patient follow-up period was 12 months. Results: There were no significant differences between both groups as regard to patient demographic data and hospital stay. Group (A) was performed in longer time; $102 \pm$ 9 vs $74 \pm 4$ in group (B). frequency of bleeding was more in group (B); 7 patients (28\%) than in group (A); one patient (4\%). Also frequency of leakage was more group (B); 6 patients $(24 \%)$ than in group (A); no patients (0\%). P-value was for bleeding and leakage; $0.049 \& 0.022$. Conclusions: Sleeve gastrectomy by laparoscopy is a safe, minimally invasive and easy operative procedure. Adding reinforcement of the whole staple line is easy method to reduce the rate and severity of the postoperative bleeding and leakage to a great extent. Additional cost due to invaginating the whole staple line may be counterbalanced by the reduction in the length of hospital stay.
\end{abstract}

Key words: Sleeve Gastrectomy, Laparoscopy, Staple line reinforcement.

\section{Introduction}

Sleeve Gastrectomy (SG) was described by Hess and Hess Marceau et al., in 1988, as the first restrictive part of a surgical malabsorptive procedure called "duodenal switch". The isolated form of the SG was described for the first time in 1993, by Johnson et al. and published in 2003. [1]

Initially Laparoscopic Sleeve Gastrectomy (LSG) proposed as a first-step procedure in high-risk patients followed by second-step laparoscopic biliopancreatic diversion and duodenal switch or laparoscopic Roux-en-Y gastric bypass, LSG, with the minimally invasive techniques and an increase in surgical experience, become widely considered as a primary restrictive bariatric procedure. The early findings from prospective and retrospective studies have been encouraging, and the potential advantages include excellent weight loss outcomes, co-morbidity resolution, the relative ease of the technique, the avoidance of a foreign body or adjustments, a shortened operating time, and immediate restriction of caloric intake. [2]

SG, whether performed by open surgery or laparoscopy (LSG), involves the creation of a small gastric reservoir based on the gastric lesser curvature over an orogastric tube, in addition to removal of a large portion of the greater curvature. LSG produces a decrease in ghrelin levels for up to 1 year, which may reduce the desire for food. [3]

A recent systematic review reported an excess weight loss of $47 \%$ and improvement in type 2 diabetes mellitus (T2DM) in over $90 \%$ of morbidly obese patients, at 13month follow-up. [4]

Notable advantages of LSG include low rates of complications (3-24\%) and mortality $(0.39 \%)$, the ease of performing the procedure, preservation of the pylorus, maintenance of physiological food passage, and avoidance of foreign material. [5]
The most commonly reported complications of LSG are bleeding, stenosis, and leaks. Bleeding can occur from gastric blood vessels during dissection of the greater curve of the stomach. Most bleeding problems associated with LSG occur from staple line after transection of the stomach. [6]

This bleeding is most likely a result of large staples used for thick tissue in the distal stomach. Large staples are not adequate to seal small vessels. [7]

Gastric leak after LSG is a serious complication, and reports of its incidence in numerous studies range from 0 $\%$ to $5.7 \%$ of patients. [8]

Many surgeons have investigated the reinforcement of staple lines as a means of reducing gastric leaks after LSG. These efforts have included staple-line over sewing, covering with omentum or jejunum, applying fibrin glue, and buttressing the staple line with a material that has been preloaded onto the stapler gun. [9]

Staple line reinforcement has been proposed as a method to reduce the incidence of both leakage and bleeding from the gastric staple line.This involve either over sewing the staple line with continuous suture or the use of tissue reinforcement (buttress) with bovine pericardium or synthetic polymers. However, no clear consensus exists regarding the efficacy of staple line reinforcement. [10]

Lalor et al., have advocated over-sewing staple line to minimize staple line dehiscence while others routinely use only buttress material or both. [11]

In a 2014 review of reinforcement of the staple line in LSG, Chen et al. suggested that a sample size of nearly 10,000 LSG procedures would be required to detect a statistically significant difference between the typically low leak rates associated with reinforcement options. [12]

In practice guidelines developed through consensus voting and published recently in the International Sleeve Gastrectomy Expert Panel Consensus Statement, 
recommendations were derived from data and knowledge based on a collective experience of 12,799 LSG cases in which the leak rate was $1.1 \%$. With respect to reinforcing the staple line, the Expert Panel achieved consensus on most topics, notably, that staple-line reinforcement reduces bleeding along the staple line and that either buttressing or over sewing the staple line are valid options. No consensus was reached on whether reinforcement reduces leak rate or reinforcement should be routinely performed. [13, 14]

Rationale of this study is to compare between non reinforced and reinforced staple line with vicryl sutures during laparoscopic sleeve gastrectomy.

\section{Patients and methods}

This prospective randomized controlled two-arm blind interventional study was conducted on 50 patients in the department of surgery at Benha University, Egypt and department of surgery at Alsabah hospital, Ministry of health, Kuwait. Patients were randomly allocated by using simple random allocation method, where 50 cards were prepared by the principal investigator and were put in closed envelops and mixed together.

After local ethical committee of Benha university approval and obtaining written fully informed patients consent after explanation of laparoscopic sleeve gastrectomy and possible advantages and disadvantages preceded selection of the type of procedure by the patient. Morbidly obese patients with, BMI $>35 \mathrm{~kg} / \mathrm{m}^{2}$ with one or more co- morbidities, or BMI $>40 \mathrm{~kg} / \mathrm{m}^{2}$ with no comorbidities were enrolled at department of surgery at Benha University, Egypt and department of surgery at Alsabah hospital, Ministry of health, Kuwait; The enrollment period was 12 months from December 2017 till April 2021 and the patient follow-up period was 12 months.

Patients were divided into two groups where 25 cases were signed as group (A); underwent Laparoscopic Sleeve Gastrectomy (LSG) with strengthening of the stapler line by v-lock suture and other 25 were signed as group (B); underwent LSG without reinforcement of the stapler line.

Patients included in the current study were morbidly obese patients with, BMI $>35 \mathrm{~kg} / \mathrm{m}^{2}$ with one or more comorbidities, or $\mathrm{BMI}>40 \mathrm{~kg} / \mathrm{m}^{2}$ with no comorbidities, Age not less than 18 and not more than 55, Any gender and Previous attempts of supervised non-surgical weight loss trials. But Patients excluded from this study were $\mathrm{ASA}_{4}$, Cancer patients at any stage, Current drug or alcohol abuse, Uncontrolled severe psychiatric illness, Disorders that may contribute to obesity, BMI not more than $55 \mathrm{~kg} / \mathrm{m}^{2}$ or Contraindications for laparoscopy.

Each patient was evaluated clinically; medical and surgical history, physical examination including vital signs, Height and weight obtained on a calibrated scale and investigated by routine blood tests, chest X-ray, ECG, thyroid and growth hormone levels assessment, upper gastrointestinal tract (GIT) endoscopy, pulmonary function studies, Other potential imaging or cardiac other referral and psychological consultation.
Operative procedure: Operations were done by the laparoscopic method under general anaesthesia by one team;

\section{Surgical technique of LSG "Reinforced stable line" (Group A):}

All patients received enoxaparin (Clexane) 40 IU night of the procedure, patient is placed on the operating table in the supine position with the operating surgeon between the legs of the patient. The preferred position for operating was using the full incline of the table in the antitrendlenberg position. However during the port placement the patient was placed in the supine position. A pneumoperitoneum is then established to $15-\mathrm{mmHg}$ pressure carbon dioxide using verrus needle. Optical entry is the preferred method of entry to the abdominal cavity with 12-mm trocar loaded with the 10- mm 0-degree scope. This scope is then changed to a 30 or 45 -degree scope. A total of 4 trocars $12-\mathrm{mm}$ are passed obliquely through the abdominal wall, including right and left upper quadrant trocars, epigastric and a supra umbilical trocars just to the left of the midline. While a $5^{\text {th }} 5$-mm trocar is inserted in the left lumbar region at the anterior axillary line.

A window is dissected at the junction of the greater curvature and the greater omentum, around $10 \mathrm{~cm}$ from the pylorus. Division of the gastroepiploic, short gastric and posterior fundic vessels is done starting at $4 \mathrm{~cm}$ proximal to the pyloric ring all the way till the angle of His using the (ultracision Harmonic scalpel) (Harmonic; Ethicon Endosurgery, Cincinnati, OH, USA).

Once the dissection part is over, a 36 Fr bougie is introduced orally by the anaesthisiologist throught the oesophagus and inside the stomach. The surgeon then guides it along the lesser curvature and into the pyloric channel and duodenal bulb. Gastric transection begins 4-6 $\mathrm{cm}$ proximal to the pylorus. A $60-\mathrm{mm}$, green or gold cartilage, is placed across the antrum through the right midepigastric port and fired. The second stapler is placed approximately 1 to $2 \mathrm{~cm}$ from the border of the lesser curvature in the direction of the gastroesophageal junction. The bougie must be held in position during this part of the procedure until completion of the stomach transection to avoid stapling across a displaced bougie.

Sequential firings of stapler along the border of the bougie on the lesser curvature completes the gastric transection at the left crus. After completing the transection, the entire staple line is inspected carefully to make sure that the staples are well formed especially at the antrum where the stomach is thickest. The staple line is reinforced by running seromuscular stitches using unidirectional absorbable v-lock $2 / 0$ sutures (Covidien, Mansfield, MA, USA) starting from angle of his down to the pylorus invaginating the staple line completely.

The transected stomach then is removed through one of the 12-mm port sites. After completion of the gastric transection the integrity of the staple line is tested by Methylene blue with the pylorus compressed by a surgical grasper. Methylene blue is injected (via the bougie) into the stomach and the staple line is inspected carefully to exclude macroscopic leaks of the suture line. The dye is 
then removed from the stomach, as is the bougie. A $18 \mathrm{Fr}$ nelaton drain is inserted along the suture line. All trocar sites are closed with 0 Vicryl (Ethicon).

Non reinforced staple line (Group B):

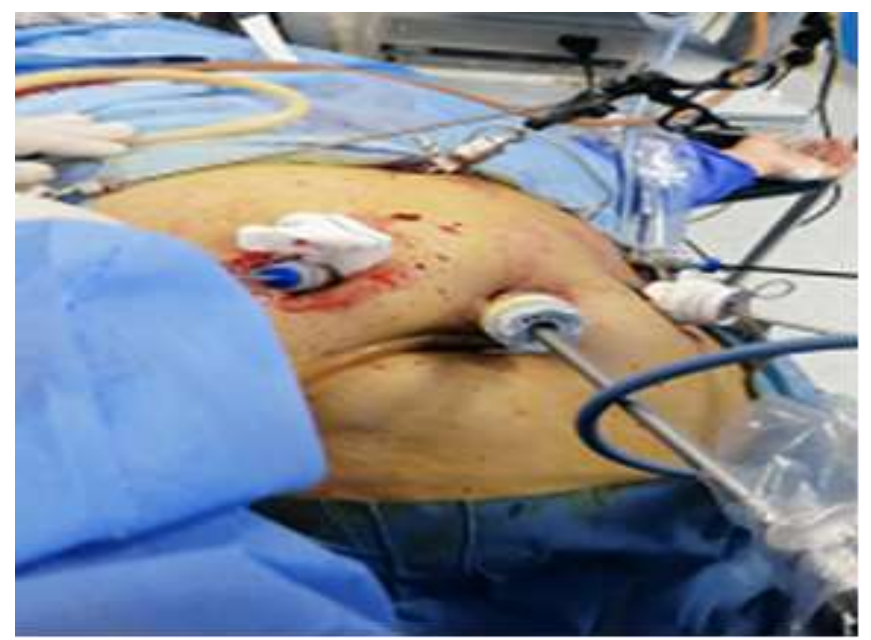

Ports site in LSG.

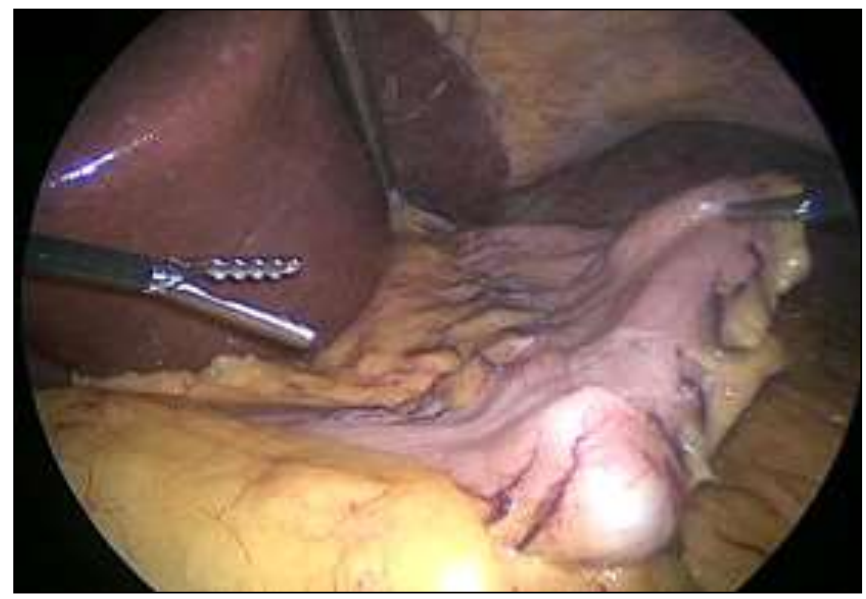

Introduction of the bougie.

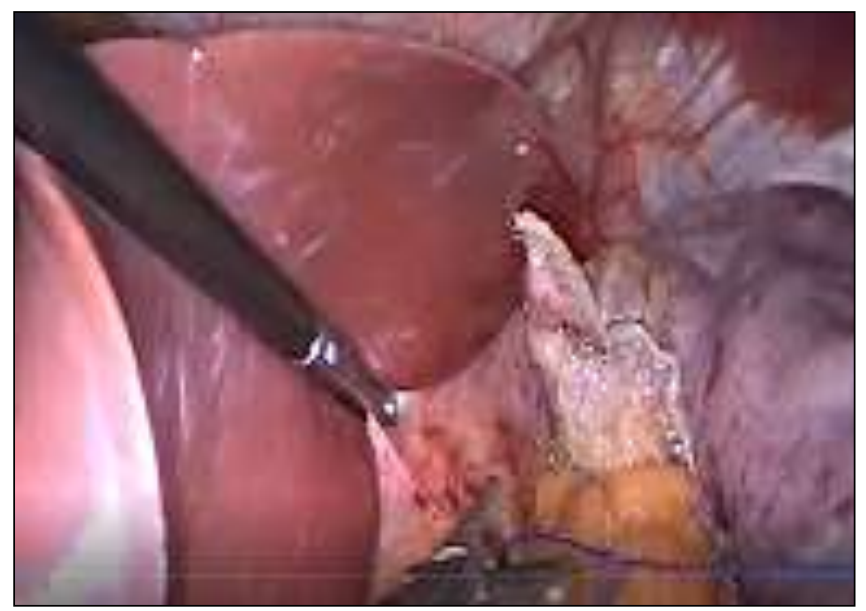

Reinforcement by v-lock $2 / 0$ sutures.
All patients in this group underwent laparoscopic sleeve gastrectomy by the same steps and same surgeon as (Group A) apart form staple line reinforcement Fig.(1).

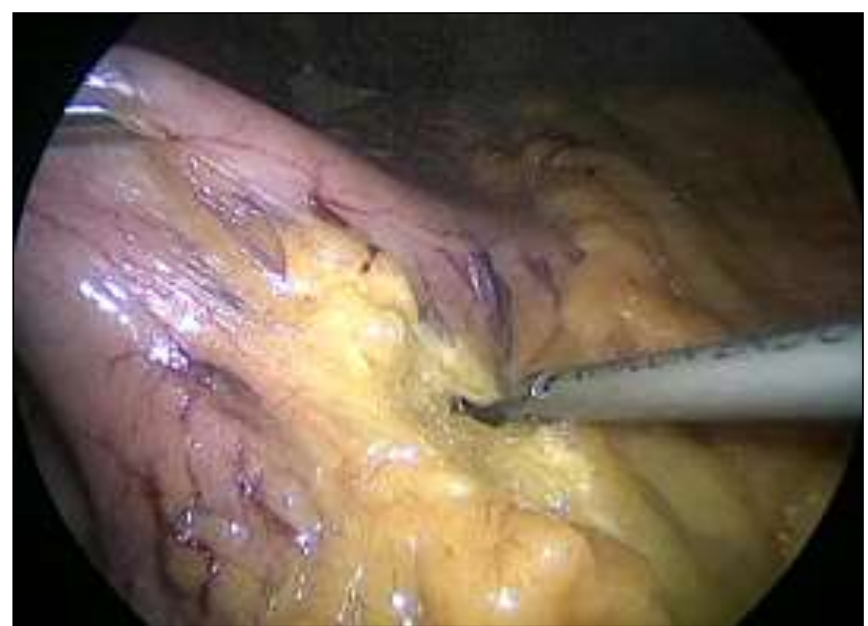

Freeing of greater curve.

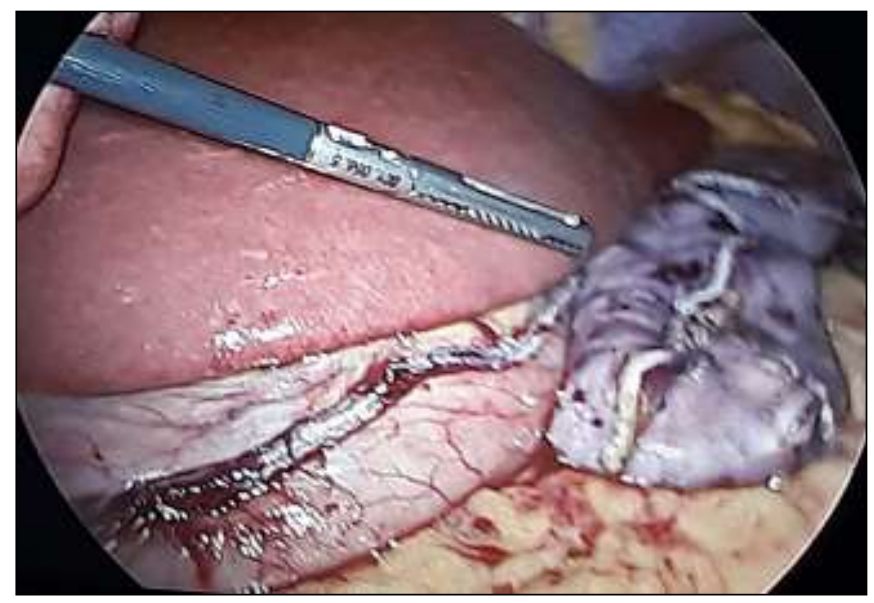

Gastric transection and stapling.

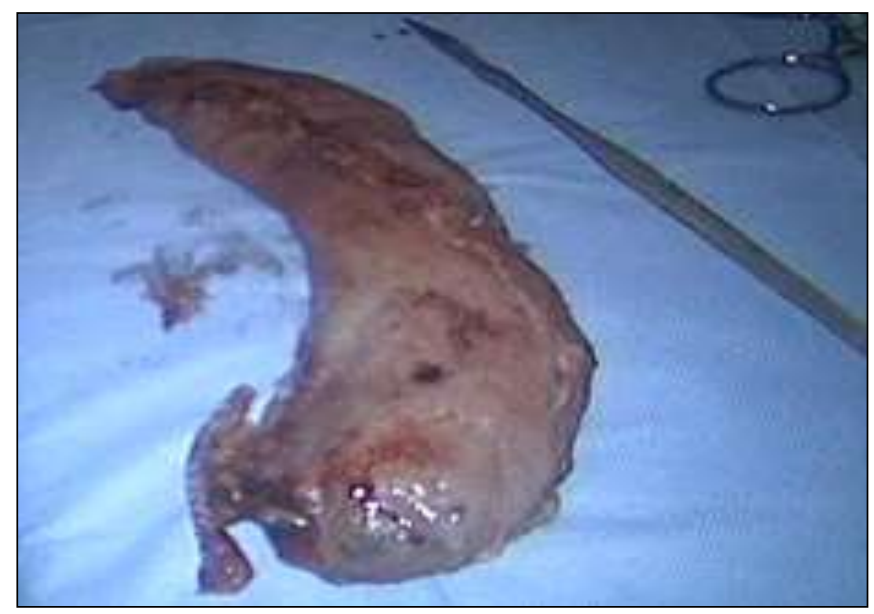

Specimen extraction.

Fig. (1) Steps of LSG "Reinforced stable line. 


\section{Postoperative Follow-up:}

All patients were closely observed for incidence of post operative leak, incidence of post operative bleeding, Duration of surgery and post operative hospital stay; Number of days after surgery patient condition permits discharge home. Complications follow up and concomitant medications or procedure were recorded. Subject weight was obtained. Nutritional assessment/counselling was performed. Changes in preoperative co-morbidities if present were reported.

The occurrence of adverse events was carefully monitored throughout the entire study period and recorded as applicable on the day of surgery, 1 week after surgery, and monthly to the $3^{\text {rd }}$ month postoperatively.

\subsection{Statistical analysis}

Data management and statistical analysis were done using SPSS vs.25. (IBM, Armonk, New York, United States). Numerical data were summarized as means and standard deviations. Categorical data were summarized as numbers and percentages. Comparisons between both groups were done using the independent t-test for numerical data. Categorical data were compared using the Chi-square test or Fisher's exact test, if appropriate. Multivariate linear regression analysis was done for the effect of using reinforced staple line on the time of surgery, controlling for all other factors. The regression coefficient and 95\% confidence intervals were calculated. All P-values were two-sided. $\mathrm{P}$ values less than 0.05 were considered significant.

\section{Results}

This randomized controlled two-arm blind interventional study was conducted in the department of surgery at Benha University. Patients included 9 male $(36 \%)$ and 16 female $(64 \%)$ in group (A) and 8 male $(32 \%)$ and 17 female $(68 \%)$ in group (B) with age around 34 years old; Mean $\pm \mathrm{SD} ; 33 \pm 8$. There were no significant differences between both groups as regard age $\&$ gender. $\mathrm{P}$ values were $0.887 \& 0.765$, respectively. By reviewing weight in the current study was around $115 \mathrm{kgs}$ with Mean \pm SD; $121 \pm 18.3$ in group (A) and 117.2 \pm 20.1 in group (B) and showed no significant difference between both groups. P-value was 0.484 . As regard to length in this study was around $165 \mathrm{~cm}$ with Mean $\pm \mathrm{SD}$; $163 \pm 10$ in group (A) and $160 \pm 11$ in group (B) and showed no significant difference between both groups. Pvalue was 0.456 . BMI of the studied patients was around 45 with Mean \pm SD; $45.74 \pm 5.02$ in group (A) and 45.71 \pm 5.06 in group $(\mathrm{B})$ and showed no significant difference between both groups. P-value was 0.984. Table (1), Fig. $(2,3)$.

Table (1) Demographic characteristics between both groups.

\begin{tabular}{|c|c|c|c|c|}
\hline & & Group A & Group B & P value \\
\hline & Males & $9(36.0)$ & $8(32.0)$ & \\
\hline Gender & Females $\mathrm{n}(\%)$ & $16(64.0)$ & $17(68.0)$ & 0.765 \\
\hline Age (years) & Mean \pm SD & $33 \pm 8$ & $33 \pm 8$ & 0.887 \\
\hline Weight (kg) & Mean \pm SD & $121 \pm 18.3$ & $117.2 \pm 20.1$ & 0.484 \\
\hline Height (cm) & Mean \pm SD & $163 \pm 10$ & $160 \pm 11$ & 0.456 \\
\hline BMI & Mean \pm SD & $45.74 \pm 5.02$ & $45.71 \pm 5.06$ & 0.984 \\
\hline
\end{tabular}

Chi-square test was used for gender \& Independent t-test was used for others.

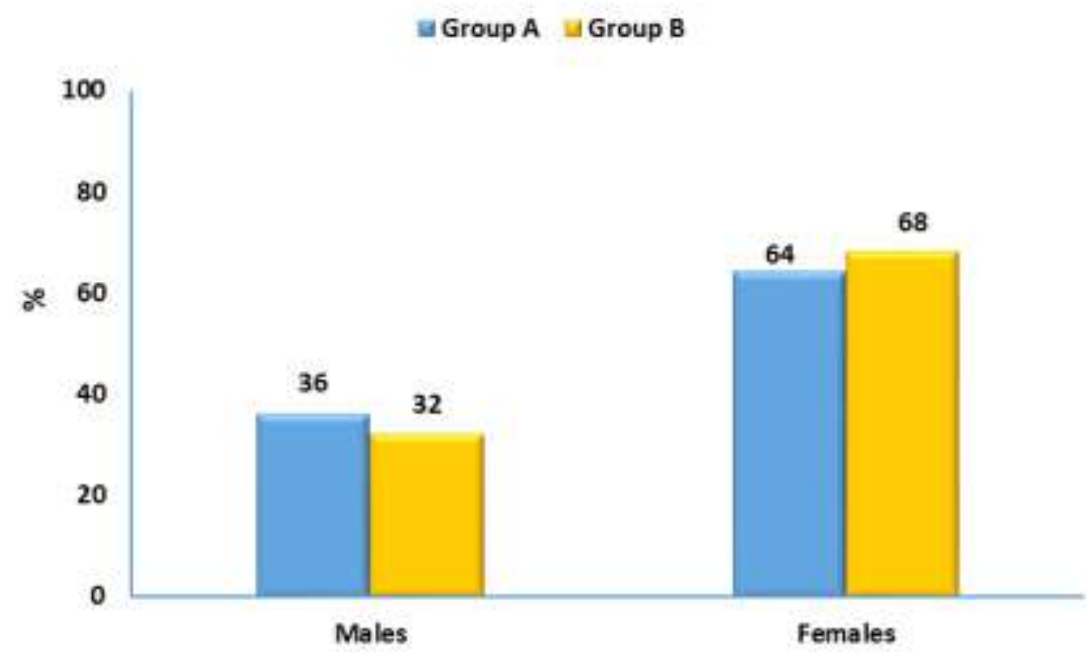

Fig. (2) Gender distribution in both groups. 


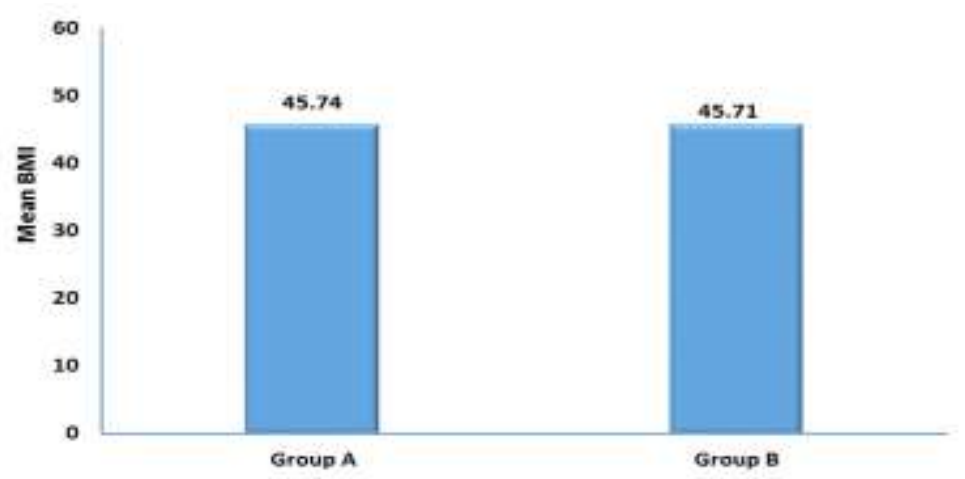

Fig. (3) BMI measurement in both groups.

Upon review the surgery time; group (A) was performed in longer time with Mean \pm SD; $102 \pm 9$ but group (B) was performed in shorter time Mean \pm SD; 74 \pm 4 and there was statistical significance between both groups; P-value was $<0.001$. Length of hospital stay was around 3 days with Mean \pm SD; $2 \pm 0$ in group (A) and 3 \pm 1 in group (B) and showed no significant difference between both groups. P-value was 0.223. Table (2), Fig. $(4,5)$.

Table (2) Time of surgery \& Length of hospital stay in both groups.

\begin{tabular}{|c|c|c|c|c|c|c|}
\hline & & Group A & $(n=25)$ & Group B & $(n=25)$ & $P$ value \\
\hline Time of surgery (minutes) & Mean \pm SD & $102 \pm 9$ & & $74 \pm 4$ & & $<0.001$ \\
\hline Hospital stay & Mean \pm SD & $2 \pm 0$ & & $3 \pm 1$ & & 0.223 \\
\hline
\end{tabular}

Independent t-test was used.

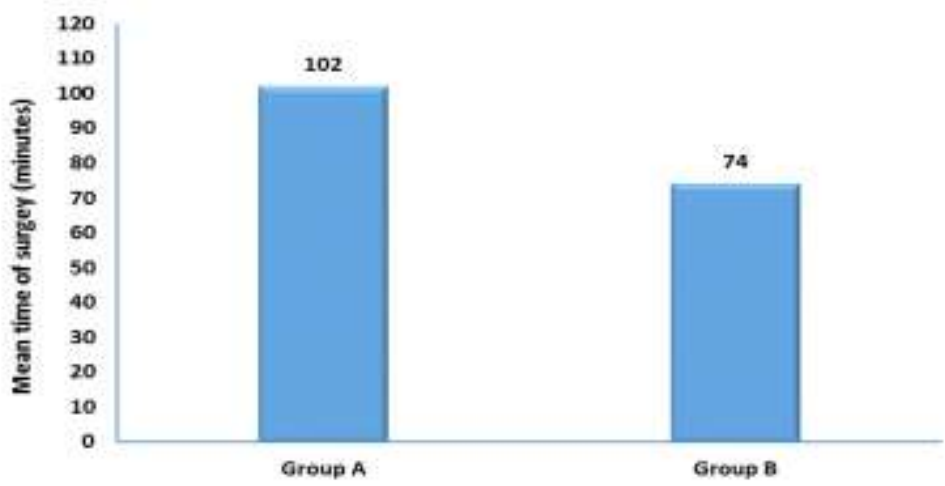

Fig. (4) Time of surgery in both groups.

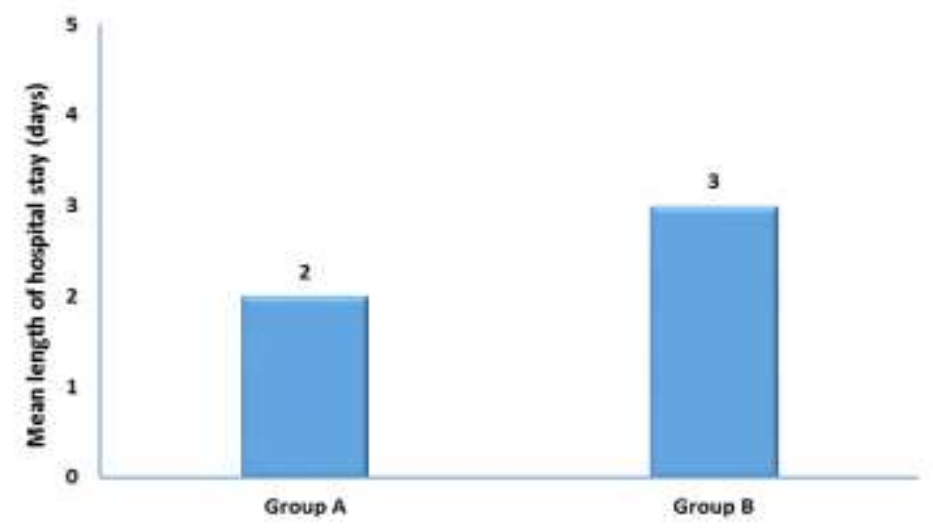

Fig. (5) Length of hospital stay both groups. 
Table (3) Frequency of postoperative complications in both groups.

\begin{tabular}{lllrrrr}
\hline & & Group A & $(\mathbf{n = 2 5 )}$ & Group B & $(\mathbf{n}=\mathbf{2 5})$ & P value \\
\hline Bleeding & $\mathbf{n}(\%)$ & & $1(4.0)$ & & $7(28.0)$ & 0.049 \\
Leakage & $\mathbf{n}(\%)$ & $0(0.0)$ & & $6(24.0)$ & 0.022 \\
\hline
\end{tabular}

Fisher's exact test was used.

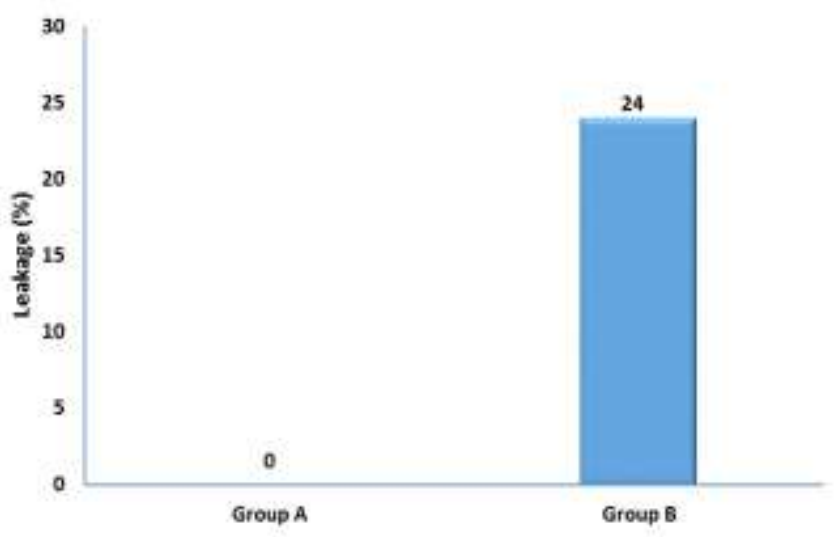

Fig. (3) Frequency of leakage in both groups.

In the present study; frequency of bleeding was more in group (B); 7 patients $(28 \%)$ than in group (A); one patient $(4 \%)$ and showed significant difference between both groups. P-value was 0.049. moreover the patient with bleeding in group (A) was treated conservatively but patients of group (B); four of them needed reexploration (two by laparoscopy and the other two by open surgery for management of bleeding) and the other 3 patients were managed conservatively. The frequency of leakage was more group (B); 6 patients $(24 \%)$ than in group (A); no patients $(0 \%)$ and showed statistical significance between both groups. P-value was 0.022 . The six patients with leakage in group (B) were managed as follow; two of them needed reexploration due to associated bleeding and leakage and the four patients were managed endoscopically by mega stent. Table (3), Fig.(6).

\section{Discussion}

The success of a laparoscopic sleeve gastrectomy is dependent on the efficacy of stapling devices utilized. All of the officially approved staplers are considered safe provided that the cartridge has been loaded correctly and is used on the appropriate tissue thickness. [15]

Staple-line reinforcement has been used with promising results in animal models and humans that underwent laparoscopic gastric bypass to reduce leakage, increase staple-line integrity and diminish staple-site bleeding. (16)

The present study included 50 patients; 9 male $(36 \%)$ and 16 female $(64 \%)$ in group (A) and 8 male $(32 \%)$ and 17 female $(68 \%)$ in group (B) with age around 34 years old; Mean $\pm \mathrm{SD} ; 33 \pm 8$. There were no significant differences between both groups as regard age $\&$ gender. $\mathrm{P}$ values were $0.887 \& 0.765$, respectively. These data were comparable to study done by "Konstantinos, et al." who mentioned that; in total, 187 patients underwent LSG; 134 women (71.7\%), 53 men
$(28.3 \%), 2.5 / 1$ ratio; median age $=36$ years $($ range $=16$ 60)). [17]

By reviewing weight in the current study; it was around $115 \mathrm{kgs}$ with Mean $\pm \mathrm{SD} ; 121 \pm 18.3$ in group (A) and $117.2 \pm 20.1$ in group (B) and showed no significant difference between both groups. P-value was 0.484 and length in this study was around $165 \mathrm{~cm}$ with Mean $\pm \mathrm{SD}$; $163 \pm 10$ in group (A) and $160 \pm 11$ in group (B) and showed no significant difference between both groups. Pvalue was 0.456 . These findings were near similar to study done by "Taha et al."; Weight $(\mathrm{kg})$ was $120.2 \pm 17.4$ in group (A) and $119.1 \pm 18.6$ in group (B) with P-value was non significant; 0.512; Height $(\mathrm{cm})$ was $168.2 \pm 8.2$ in group (A) and $167.3 \pm 8$ in group (B) with $\mathrm{P}$-value was non significant; 0.303. [18]

Indications of bariatric surgery include BMI of 40 $\mathrm{kg} / \mathrm{m} 2$ or higher or a BMI between 35 and $40 \mathrm{~kg} / \mathrm{m} 2$ with at least two obesity-related comorbidities, According to National Institutes of Health guidelines. [19]

The preoperative BMI of the studied patients was around 45 with Mean \pm SD; $45.74 \pm 5.02$ in group (A) and $45.71 \pm 5.06$ in group (B) and showed no significant difference between both groups. P-value was 0.984 . These findings were comparable to study done by "Andreas, et al.," between August 2007 and March 2015, 118 patients underwent LSG. The mean Preoperative BMI was 54.6 $\mathrm{kg} / \mathrm{m} 2$. [20]

Upon review the surgery time; group (A) was performed in longer time with Mean \pm SD; $102 \pm 9$ but group (B) was performed in shorter time Mean \pm SD; 74 \pm 4 and there was statistical significance between both groups; P-value was $<0.001$. Our operative time was more longer than mentioned by "Taha et al."; the average surgical time was statistically significantly shorter in the patients who underwent LSG without oversewing of the staple line $(44.3 \pm 5.5 \mathrm{~min}$ in group 1 vs $51.3 \pm 4.3 \mathrm{~min}$ in 
group 2, p < 0.01). Our longer time could be explained by that we were early in the learning curve. [18]

In the current work; length of hospital stay was around 3 days with Mean \pm SD; $2 \pm 0$ in group (A) and 3 \pm 1 in group (B) and showed no significant difference between both groups. P-value was 0.223 . These results were in consistent with the results obtained from "Hany and Ibrahim"; who stated that the Mean hospital stay (days) $1.92 \pm 0.33$ in group (A) and $1.97 \pm 0.42$ in group (B) with P-value was 0.068 . This short stay because laparoscopy is minimal invasive surgery. [21]

There are several complications associated with LSG such as leak due to staple-line disruption, bleeding requiring reoperation or transfusion and postoperative strictures requiring endoscopic or surgical intervention. $[22,23]$

In the present study; frequency of bleeding was more in group (B); 7 patients (28\%) than in group (A); one patient $(4 \%)$ and showed significant difference. This bleeding rate was comparable to study performed by "Hany and Ibrahim"; who observed that bleeding in 2 patients $(0.4 \%)$ of group (A) and 7 patients $(1.5 \%)$ in group (B) with $\mathrm{P}$ value was 0.178 . [21]

Bleeding rate of our study was comparable to study performed by "Taha et al." who reported that; staple-line bleeding rate was significantly less in cases underwent reinforced LSG compared with patients underwent non reinforced LSG (2\% in group (A) vs $9 \%$ in group (B), p < 0.05).[18]

Staple-line leak is another serious complication with incidence reported to be up to $2-5 \%$. [24, 25] GIT leakage after bariatric surgery has been identified as an independent risk factor associated with perioperative death. [26]

We had zero leakage in group (A) but frequency of leakage in group (B) was 6 patients (24\%); there was statistical significance between both groups; P-value was 0.022 . These results were in complete accordance with "Hany and Ibrahim" who reported; Leak was 0 in group (A) and 8 patients $(1.7 \%)$ in group (B) with $\mathrm{P}$ value was 0.008. [21]

There are many causes of such leak; probably due to the increased dissection required by re-operative surgery, with a resulting increased risk of injury and ischemia to the tissues. The EG junction has been reported as the usual site of leak after LSG. [27, 28]

In the current work; Use of V-Loc $2 / 0$ reduced the bleeding and leakage to a great extent and these results were approved by " Nemecek et al." [29]

These results are supportive by multiple randomized controlled trials reports which demonstrated that the staple line reinforcement in LSG had benefits over the postoperative staple-line hemorrhage and leakage. [30-32]

\section{Conclusion}

Sleeve gastrectomy by laparoscopy is a safe, minimally invasive and easy operative procedure. Adding reinforcement of the whole staple line is easy method to reduce the rate and severity of the postoperative bleeding and leakage to a great extent. Additional cost due to invaginating the whole staple line may be counterbalanced by the reduction in the length of hospital stay.

\section{References}

[1] D.Johnston, J. Dachtler, H. Sue-Ling and 1.Martin. The Magenstrasse and Mill operation for morbid obesity. Obes. Surg.vol.5,pp. 13: 10-16, 2003.

[2] S.Brethauer, J. Hammel and P.Schauer. Systematic review of sleeve gastrectomy as staging and primary bariatric procedure. Surg. Obes. Relat. Dis5.vol.5,pp.469-75,2009.

[3] S.Karamanakos, K. Vagenas and F. Kalfarentzos. Weight loss, appetite suppression, and changes in fasting and postprandial ghrelin and peptide-YY levels after Roux-en-Y gastric bypass and sleeve gastrectomy: a prospective, double blind study. Ann. Surg.vol.4,pp.247 (3): 401-7,2008.

[4] R.Gill, D. Birch and X. Shi. Sleeve gastrectomy and type 2 diabetes mellitus: a systematic review. Surg. Obes. Relat. Dis6.vol.1,pp. 707-13, 2010.

[5] C.Lee P., Cirangle and G.Jossart. Vertical gastrectomy for morbid obesity in 216 cases: report of two-year results. Surg. Endos.vol.2,pp.21 (10): 18106,2007 .

[6] J. Armstrong and S.O'Malley: Outcomes of sleeve gastrectomy for morbid obesity: a safe and effective procedure? Int. J. Surg.vol.5,pp.8 (1): 6971,2010.

[7] R.Baker, J. Foote and P. Kemmeter. The science of stapling and leaks. Obes. Surg.vol.4,pp. 14 (10): 1290-8,2004.

[8] D.Fuks, P. Verhaeghe and O.Brehant. Results of laparoscopic sleeve gastrectomy: a prospective study in 135 patients with morbid obesity. Surgery.vol.7,pp. 145 (1): 106-13,2009.

[9] M.Daskalakis, Y.Berdan and S.Theodoridou. Impact of surgeon experience and buttress material on postoperative complications after laparoscopic sleeve gastrectomy. Surg. Endosc. Vol,5,pp.25 (1): 8897,2011 .

[10] S.Richdeep, S.Noah, D.Mike, S.Xinzhe, V.Andrey, M.Arya, W. Daniel and K.Shahzeer. Laparoscopic Sleeve Gastrectomy with Staple line reinforcement in 116 consecutive morbidly obese patients. Obese. SurgDoi.vol.5,pp. 10.1007/s11695012-0598-z,2012.

[11] P.F.Lalor, O.N. Tucker and S.L.Szomstein: Complications after laparoscopic sleeve gastrectomy. Surg. Obes. Relat. Dis.vol.4,pp.4 (1): 33-38,2008.

[12] B.Chen, A.Kiriakopoulos, D.Tsakayannis, MS. Wachtel, D. Linos and E. Frezza.Reinforcement does not necessarily reduce the rate of staple line leaks after sleeve gastrectomy. A review of the literature and clinical experiences. Obes. Surg.vol.7,pp.19: 16672,2014 .

[13] D. Bellanger and F. Greenway. Laparoscopic sleeve gastrectomy, 529cases without a leak: shortterm results and technical considerations. Obes. Surg.vol.6,pp.21:146-50.2011. 
[14] R.J. Rosenthal and I.S. Panel. International Sleeve Gastrectomy Expert Panel Consensus Statement: best practice guidelines based on experience of $>12,000$ cases. Surg. Obes. Relat. Dis.vol.2,pp.8 (1): 8-19,2012.

[15] S. Brown and E.Woo. Surgical stapler-associated fatalities and adverse events reported to the food and drug administration. J. Am. Col. Surg.vol.9,pp.199:374-381,2004.

[16] N.Nguyen, M. Longoria, S.Welbourne, A. Sabio and S.Wilson. Glycolide copolymer staple-line reinforcement reduces staple site bleeding during laparoscopic gastric bypass. Arch Surg1.vol.,pp.40:773-778, 2015.

[17] M. Konstantinos, M. Evangelos, D.Dimitris, A.Calliope, A.Leonidas, A.Konstantinos, Emmanuel L. and Z. George. Prospective comparative study of efficacy of staple-line reinforcement in LSG Surg. Endosc.vol.4,pp.25: 3526-3530; DOI 10.1007/s00464011-1752-8, 2011.

[18] O.Taha, M.Abdelaal, M. Talaat and M.Abozeid. A Randomized Comparison Between Staple-Line Oversewing Versus No Reinforcement During Laparoscopic Vertical Sleeve Gastrectomy in OBES. SURGDOI.vol.5,pp.10.1007/s11695-017-2835$\mathrm{y}, 2017$.

[19] B.Wolfe, E. Kvach and R.Eckel: Treatment of Obesity: Weight Loss and Bariatric Surgery. Circulation Research.vol.6,pp.118 (11): 1844-1855, 2017.

[20] P.Andreas, L.Philipp , N.Jennifer and R. Karl . Comparison of Sleeve Gastrectomy versus Omega Loop Gastric Bypass in a Mainly Super-Obese Patient Group - Short- and Mid-Term Results. Official journal of metabolic and bariatric surgery.vol.6,pp.11 (6): 99-100,2015.

[21] M. Hany and M.Ibrahim: Comparison Between Stable Line Reinforcement by Barbed Suture and Non-reinforcement in Sleeve Gastrectomy: a Randomized Prospective Controlled Study in Obesity Surgery.vol.6,pp.https://doi.org/10.1007/s11695-0183175-2,2018.

[22] J.Noah, A. Smith and D.Birch. The metabolic effects of laparoscopic sleeve gastrectomy: a review. J. Minim Invasive Surg. Sci.vol.5,pp. 2 (3): 3-7, 2013.

[23] K.Sarkhosh, D. Birch and A.Sharma Complications associated with laparoscopic sleeve gastrectomy for morbid obesity: a surgeon's guide. Can J. Surg.vol.7,pp.56 (5): 347-52 . , 2013.

[24] P.Gentileschi, I. Camperchioli and S.D'Ugo: Staple-line reinforcement during laparoscopic sleeve gastrectomy using three different techniques: a randomized trial. Surg. Endosc.vol.5,pp. 26 (9): 26239, 2012.

[25] F.C.Campanile, C.E. Boru and M.L.Rizzello. Acute complications after laparoscopic bariatric procedures: update for the general surgeon. Langenbeck's Arch Surg.vol.2,pp.398 (5): 669-86, 2013.
[26] A.Z.Fernandez, E.J.DeMaria, D.S.Tichansky, J.M. Kellum, J.A. Wolfe and J.E.Meador. Multivariate analysis of risk factors for death following gastric bypass for morbid obesity. Ann. Surg.vol.2,pp.239: 698-703, 2004.

[27] G.Dapri, C.Vaz, G. Cadie' and J.Himpens: A prospective randomized study comparing two different techniques for laparo- scopic sleeve gastrectomy. Obes. Surg.vol.1,pp.17:143541,2007.

[28] G. Casella, E. Soricelli and M.Rizzello. Nonsurgical treatment of staple line leaks after LSG. Obes. Surg.vol.2,pp.19(7): 821-6,2009.

[29] E.Nemecek, L. Negrin and C. Beran. Application of V-Loc device for GIT sutures: a preliminary study. Surg. Endosc.vol.6,pp.27 (10): 3830-4, 2013.

[30] S.S.Shah, J.S. Todkar and P.S.Shah. Buttressing staple line: a randomized comparison between stapleline reinforcement versus no reinforcement during sleeve gastrectomy. Obes. Surg.vol.5,pp.24 (12): 2014-20,2014.

[31] G.Sroka, D.Milevski and D.Shteinberg: Minimizing hemorrhagic complications in laparoscopic sleeve gastrectomy a randomized controlled trial. Obes. Surg.vol.2,pp.25 (9): 1577-83, 2015.

[32] Z.Wang, X. Dai and H.Xie: The efficacy of staple line reinforcement during laparoscopic sleeve gastrectomy: a meta-analysis of randomized controlled trials. Int. J. Surg. (London, England.vol.8,pp. 25: 145-52, 2016. 